Keywords: colorectal cancer; epithelial-mesenchymal transition; dedifferentiation; desmoplastic reaction; cancer-associated fibroblasts; cancer microenvironment

\title{
Prognostic impact of histological categorisation of epithelial-mesenchymal transition in colorectal cancer
}

\author{
H Ueno ${ }^{*}{ }^{1}$, E Shinto ${ }^{1}$, Y Kajiwara ${ }^{1}$, S Fukazawa ${ }^{1}$, H Shimazaki $^{2}$, J Yamamoto ${ }^{1}$ and K Hase ${ }^{1}$ \\ ${ }^{1}$ Department of Surgery, National Defense Medical College, Saitama, Japan and ${ }^{2}$ Department of Laboratory Medicine, \\ National Defense Medical College, Saitama, Japan
}

Background: The crosstalk between cancer cells and stroma is involved in the acquired capability for metastasis through the induction of epithelial-mesenchymal transition (EMT). We aimed to clarify the prognostic value of the histological category of EMT in colorectal cancer (CRC).

Methods: Tumour EMT was graded into one of three histological categories on the basis of integrated assessment of poorly differentiated clusters and pro-EMT desmoplasia at the leading edge of the primary tumour (Histology ${ }^{\mathrm{EMT}}$ ). Stage II and III CRC patients (cohort 1, N=500) and stage IV patients (cohort 2, N=196) were retrospectively analysed.

Results: In cohort 1, patients were stratified into three groups with widely different disease-free survival rates (95\%, 83\% and 39\%) on the basis of Histology ${ }^{\mathrm{EMT}}(P<0.0001)$. In cohort 2, Histology ${ }^{\mathrm{EMT}}$ significantly stratified overall survival of patients irrespective of metasectomy. Multivariate analyses indicated that Histology ${ }^{\mathrm{EMT}}$ had a strong prognostic impact independent of staging factors. Statistically, Histology ${ }^{\text {EMT }}$ had a better prognostic stratification power than $\mathrm{T}$ and $\mathrm{N}$ stages; however, in cohort 2, the power of $\mathrm{M}$ substage was superior.

Conclusions: A histological model to categorise EMT by integrated assessment of dedifferentiation and desmoplastic environment is a potent prognostic index independent of staging factors.

Staging and grading of tumours provides an accurate description of different tumour types, thereby contributing to the prognosis of patients with malignant tumours (Thiery, 2002). The stage describes the extent of spread of a tumour as local or distant from the primary site, whereas the grade is a number reflecting the morphology and proliferative capacity of the primary tumour. At present, the pathological stage is believed to represent the most important prognostic factor for colorectal cancer (CRC) patients (Wolpin and Mayer, 2008). Historically, cancer staging and treatment planning was based solely on the anatomic extent of the cancer (Edge and Compton, 2010), as is reflected in current international guidelines (National Comprehensive Cancer Network, 2014). However, the rapidly increasing specific knowledge of cancer biology could establish a new methodology for grading tumours that provides prognostic information independent of tumour stage, which must be incorporated into cancer prognostic models (Edge and Compton, 2010).

A developmental regulatory programme, referred to as epithelial-mesenchymal transition (EMT), has become prominently implicated as a means by which transformed epithelial cells can acquire the ability to invade and disseminate (Hanahan and Weinberg, 2011). It is widely believed that in human CRC, a loss of differentiation is induced under the EMT programme at the tumour-host interface, enabling cellular detachment, dissemination and eventually metastasis (Brabletz et al, 2005; Karagiannis et al, 2012). The degree of tumour differentiation has long been employed in CRCs for grading tumours (Sobin et al, 2009); however, this does not necessarily assess EMT, which requires a methodology for characterising the morphological heterogeneity at the leading edge of a tumour. In this respect, one of the most 
promising methods for assessing dedifferentiation and the migratory phenotype of a tumour is to quantify poorly differentiated clusters (PDCs). This method is expected to be less subjective and more informative for prognostic evaluation than conventional tumour grading (Ueno et al, 2012, 2014).

Recent findings highlight that paracrine signalling between tumour and host cells in the cancer microenvironment has a critical role in determining EMT (McAllister and Weinberg, 2010). In the cancer microenvironment, cancer-associated fibroblasts (CAFs) have a central role in mediating EMT of carcinoma cells (Kalluri and Zeisberg, 2006; Karagiannis et al, 2012), thereby facilitating the progression of carcinoma cells towards a dedifferentiated and more malignant state in a direct or indirect manner through extracellular matrix (ECM) remodelling (Figure 1). Desmoplastic reaction (DR) represents the histological result of ECM remodelling generated by CAFs. Desmoplastic reaction is morphologically categorised on the basis of the presence of specific types of ECM components, such as keloid-like collagen and myxoid stroma, which are histological features closely related to the function of CAFs in the desmoplastic microenvironment in CRC (Ueno et al, 2002, 2004).

Grading of tumours by histologically characterising the local environment associated with the EMT status has rarely been reported. On the basis of our recent knowledge of cancer biology, comprehensive assessment of the tumour dedifferentiation phenotype and desmoplastic environment may be a useful

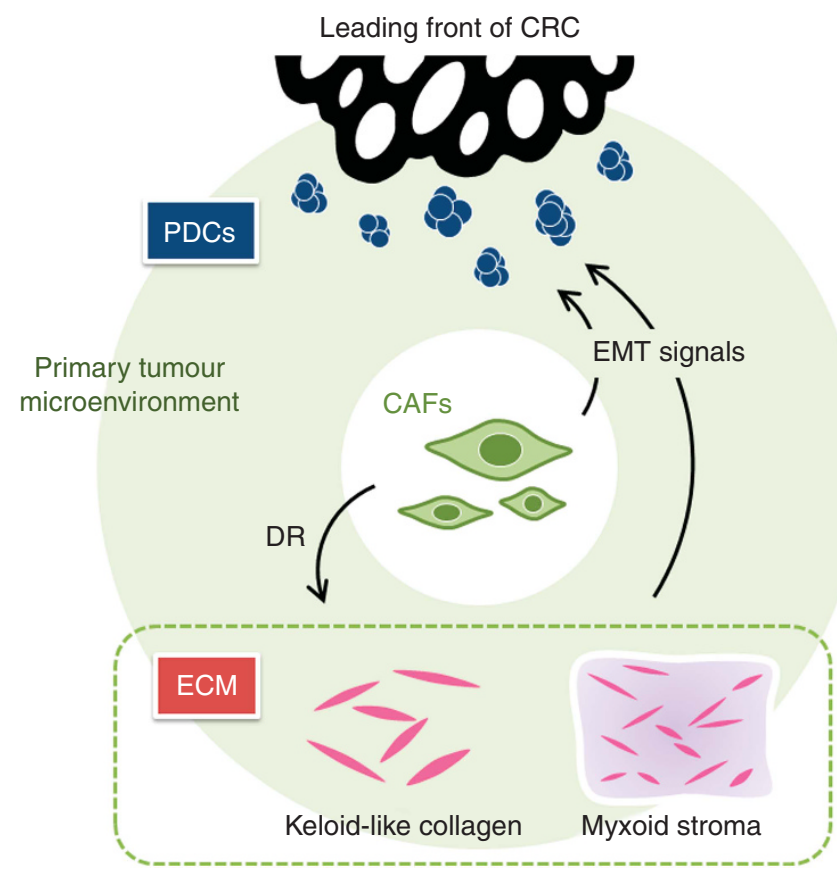

Figure 1. Schema of histological alteration at the desmoplastic invasive front of colorectal cancer associated with epithelialmesenchymal transition. Increasing evidence suggests that heterotypic interactions of cancer cells with adjacent tumour-associated stroma cells can induce expression of malignant cell phenotypes. Recent basic oncology studies have demonstrated that CAFs have a major role in modulating the metastatic capacity of most cancers and determine the oncological outcome of tumours directly and indirectly in the process of DR through the formation of various ECM types, which cause EMT signals to induce tumour cells into a dedifferentiated phenotype. In the present study, PDCs and ECMs, such as keloid-like collagen and myxoid stroma, were comprehensively assessed as representing the microenvironment associated with the EMT status. Abbreviations: $\mathrm{CAFs}=$ cancer-associated fibroblasts; $\mathrm{DR}=$ desmoplastic reaction; $\mathrm{ECM}=$ extracellular matrix; $\mathrm{EMT}=$ epithelial-mesenchymal transition. approach to evaluate an individual tumour's EMT potential. In the present study, we attempted to histologically categorise tumours on the basis of PDCs and DR at the leading edge of the primary tumour (Histology ${ }^{\mathrm{EMT}}$ ) on the premise that Histology ${ }^{\mathrm{EMT}}$ represents the potential of induction of EMT in CRC. Our main objective was to investigate whether Histology ${ }^{\text {EMT }}$ can become a new grading method leading to a prognostic evaluation system independent of tumour staging.

\section{PATIENTS AND METHODS}

\section{Patients}

Cohort 1. A total of 500 consecutive patients with stage II or III CRC who had undergone curative intent surgery between 2000 and 2005 were enrolled; patents with T1 CRC were excluded. The median age of the patients was 66 years (range, 18-96); 280 and 220 tumours were resected from male and female patients, respectively. No patient received preoperative adjuvant therapy. Regarding postoperative adjuvant chemotherapy, 245 patients received chemotherapy, 96 received $5-\mathrm{FU} / \mathrm{LV}, 56$ received UFT/ LV and 93 received oral anticancer drugs such as UFT, 5'-DFUR, HCFU or 5-FU. No adjuvant therapy was administered to 247 patients, and detailed information regarding postoperative adjuvant therapy could not be obtained for 8 patients. The median follow-up period of 378 survivors was 68 months.

Cohort 2. In cohort 2, 196 consecutive patients with stage IV CRC who underwent surgery for their primary tumours between 1997 and 2007 were included. This cohort comprised 64 patients with resectable distant metastasis and 132 patients with unresectable diseases. The median age of the patients was 65 years (range, 34-91 years) and 122 patients (62.2\%) were male. The most frequent pattern of distant metastasis was liver only (89), followed by lymph node only (18), liver and lungs (17), peritoneal dissemination (15), liver and peritoneal dissemination (13) and lungs only (9).

In the resectable stage IV group, 39 patients received postoperative adjuvant chemotherapy [UFT/LV (21), 5-FU/LV (8), CPT-11 (4), intrahepatic artery 5-FU infusion (3), oral anticancer drugs (3)], and no adjuvant therapy was administered to 25 patients. During the study period, oxaliplatin was not approved for administration as an adjuvant in Japan; it was first approved to be administered for unresectable CRC patients in 2005. In this study, 16 patients $(13.6 \%)$ in the unresectable group received chemotherapy with a FOLFOX regimen. The median follow-up period of 24 survivors was 77 months. Detailed prognostic information, including the day of death, was obtained for 122 patients (92.4\%).

Histological assessments. With regard to conventional histopathological factors including $\mathrm{pT}, \mathrm{pN}$, tumour grade and lymphatic and venous invasion, pathological diagnoses made in routine practice and recorded in pathological reports were used for analysis. Lymphatic and venous invasion had been diagnosed with a four-grade system (none, mild, moderate and severe) (Japanese Society for Cancer of the Colon and Rectum, 2009). In the present study, none and mild degrees were treated as low grade and moderate and severe degrees were treated as high grade.

One of the authors (HU) pathologically reviewed primary tumours to evaluate PDCs and DR with no prior knowledge of the patients' clinical outcomes. Haematoxylin-eosin (HE)-stained glass slides prepared from a single longitudinal section of the whole tumour, including its deepest part, were microscopically scanned to identify the area to be assessed for PDCs and DR. Each parameter was evaluated according to the below-mentioned criteria.

Poorly differentiated clusters. Poorly differentiated clusters were defined as cancer cell clusters comprising $\geqslant$ five cancer cells 
infiltrating the stroma and lacking gland formation (Figure 2; Ueno et al, 2012, 2014). After selecting one field where PDCs were the most intensive, the number of clusters was counted under a $20 \times$ objective lens and the grade was determined on the basis of the number of clusters present. Tumours with $<5,5-9$ or $\geqslant 10$ clusters were classified as G1, G2 or G3, respectively.

Desmoplastic reaction. Desmoplastic reaction was histologically classified into one of three categories (mature, intermediate and immature) on the basis of the existence of keloid-like collagen and myxoid stroma in the reactive fibrous zone at the advancing edge of the tumour (Figure 2; Ueno et al, 2004). Keloid-like collagen consisted of broad bundles of hypocellular collagen with brightly eosinophilic hyalinization, typically observed in a keloid (Ueno et al, 2002). Myxoid stroma can be defined as an amorphous stromal substance composed of an amphophilic or slightly basophilic material that is usually intermingled with randomly oriented keloid-like collagen.

Desmoplastic reaction was regarded as mature when fibrotic stroma did not contain keloid-like collagen or myxoid stroma and was composed of fine mature collagen fibres stratified into multiple
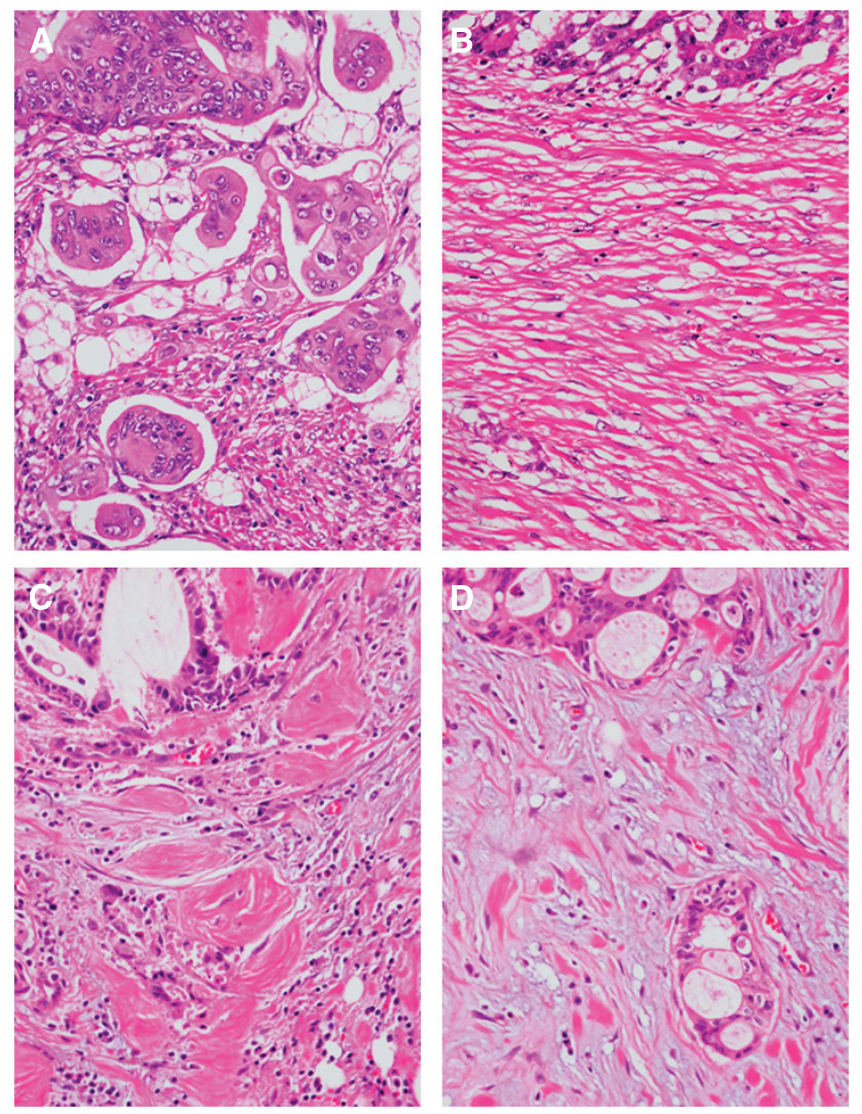

Figure 2. Poorly differentiated clusters (PDCs) and the categorisation of desmoplastic reaction (DR) in colorectal cancer. (A) Poorly differentiated clusters, which are cancer cell clusters located in the stroma, comprising $\geqslant$ five cancer cells and lacking gland formation. (B) Mature DR denotes fibrotic stroma not accompanied by keloid-like collagen and myxoid stroma, typically composed of fine collagen fibres stratified into multilayers. (C) Keloid-like collagens, that is, broad bands of collagen with brightly eosinophilic hyalinization, similar to those seen in a keloid, appear around cancer nests at the invasive front (intermediate DR). (D) Abundant amorphous extracellular matrix with keloid-like collagen forms the component of myxoid stroma at the leading edge of the tumour (immature DR). (All: $40 \times$ objective lens, haematoxylin-eosin). layers. When keloid-like collagen was intermingled with mature stroma, the fibrotic stroma was designated as undergoing intermediate maturation. The stroma with myxoid changes was regarded as immature stroma. In each case, the stroma was classified according to the most immature stromal area.

Categorisation criteria for Histology ${ }^{\mathrm{EMT}}$. Using PDC and DR as components, a three-tiered categorisation system (Histology ${ }^{\mathrm{EMT}}$ ) was established as a model to estimate the potential of EMT of a tumour: category A included tumours with both G1 PDC and mature-type stroma; category C included tumours with both G3 PDC and immature-type stroma; and category B indicated tumours with other types of histology.

Statistical analyses. Survival rates were calculated by the KaplanMeier method and comparisons were made by the log-rank test. After categorisation, each clinical and pathological variable was entered into Cox proportional hazards regression analysis to determine which parameter had an independent effect on postoperative survival. The associations among prognostic factors and their associations with recurrence were analysed by $\chi^{2}$ tests. Prognostic stratification of prognostic parameters was evaluated by the Akaike information criterion (AIC; Akaike, 1973). Akaike information criterion was analysed using a Cox proportional regression model to identify the parameter with the highest ability for discrimination of survival outcomes. The optimum model, the simplest effective model with the smallest information loss when predicting the outcome, gives the lowest AIC value.

Statistical analyses were performed with SPSS Statistics 17.0 (SPSS, Inc., Chicago, IL, USA), Stata/SE 10 (StataCorp LP, College Station, TX, USA) and StatView ver.5.0 (SAS Institute, Inc., Cary, NC, USA).

\section{RESULTS}

Incidence of each category of Histology ${ }^{\mathrm{EMT}}$. There was a significant difference in the distribution of PDC grade and DR categorisation between cohorts 1 and 2 (both $P<0.0001$ ). However, both parameters were significantly associated with overall survival (OS) in both cohorts (Table 1). Multivariate analyses indicated independent prognostic impacts of PDC and DR.

According to Histology ${ }^{\mathrm{EMT}}, 128,314$ and 58 patients in cohort 1 and $8,103,85$ patients in cohort 2 were classified as having tumours of categories $\mathrm{A}, \mathrm{B}$ and $\mathrm{C}$, respectively. As shown in Table 2, Histology ${ }^{\mathrm{EMT}}$ was significantly associated with various clinicopathological prognostic factors, including primary tumour histology (tumour differentiation grade and lymphatic and venous invasion) and $\mathrm{T}$ and $\mathrm{N}$ stages in cohort $1(P \leqslant 0.0001-0.002)$ and lymphatic invasion, $\mathrm{T}$ and $\mathrm{N}$ stages and $\mathrm{M}$ substage (M1a/M1b) in cohort $2(P \leqslant 0.0001-0.04)$.

\section{Prognostic impact of Histology ${ }^{\text {EMT }}$}

Cohort 1. Figure 3 shows the Kaplan-Meier estimates for diseasefree survival (DFS) and OS after surgery in patients stratified into the three groups according to Histology ${ }^{\mathrm{EMT}}$. The 5-year DFS rates were $95.1 \%$ for category A, $82.8 \%$ for category B and $38.6 \%$ for category C, respectively (Figure 3). Similarly, the 5-year OS rates were highest for category A (91.1\%), followed by categories B (78.3\%) and C (50.2\%).

The incidence of recurrence in the liver was $1.6 \%$ for category A, $9.2 \%$ for category B and $20.7 \%$ for category C $(P<0.0001)$. Similarly, the incidence of recurrence in the lung was highest for category C (27.6\%), followed by category B (7.0\%) and category A (3.9\%; $P<0.0001)$. This trend was similar for recurrence in the lymph node/local recurrence and peritoneum (both $P<0.0001$ ). 
Table 1. Prognostic impact of poorly differentiated clusters (PDCs) and desmoplastic reaction (DR) on overall survival

\section{Cox proportional hazards model}

\begin{tabular}{|c|c|c|c|c|c|c|}
\hline \multirow{2}{*}{\begin{tabular}{|l|} 
\\
Parameters \\
\end{tabular}} & \multirow[b]{2}{*}{ Categories } & \multirow[b]{2}{*}{ No of cases } & \multirow[b]{2}{*}{ 5-year OS (\%) } & \multicolumn{2}{|c|}{ Univariate } & \multirow{2}{*}{$\begin{array}{c}\text { Multivariate } \\
P\end{array}$} \\
\hline & & & & HR $(95 \% \mathrm{Cl})$ & $P$ & \\
\hline \multicolumn{7}{|l|}{ Cohort 1} \\
\hline $\begin{array}{l}\text { PDC } \\
\text { DR }\end{array}$ & $\begin{array}{l}\mathrm{G} 1 \\
\mathrm{G} 2 \\
\mathrm{G} 3 \\
\text { Mature } \\
\text { Intermediate } \\
\text { Immature }\end{array}$ & $\begin{array}{r}156 \\
198 \\
146 \\
248 \\
170 \\
82\end{array}$ & $\begin{array}{l}90.1 \\
81.6 \\
61.4 \\
88.8 \\
73.3 \\
57.2 \\
\end{array}$ & $\begin{aligned} & \text { Ref. } \\
2.1 & (1.2-3.6) \\
4.7 & (2.8-8.0) \\
& \text { Ref. } \\
2.3 & (1.5-3.6) \\
4.5 & (2.8-7.1)\end{aligned}$ & $\begin{array}{r}0.0090 \\
<0.0001 \\
\\
<0.0001 \\
<0.0001\end{array}$ & $\begin{array}{r}<0.0001 \\
0.0015\end{array}$ \\
\hline \multicolumn{7}{|l|}{ Cohort 2} \\
\hline PDC & $\begin{array}{l}\mathrm{G} 1 \\
\mathrm{G} 2 \\
\mathrm{G} 3 \\
\text { Mature } \\
\text { Intermediate } \\
\text { Immature }\end{array}$ & $\begin{array}{r}12 \\
42 \\
142 \\
32 \\
71 \\
93\end{array}$ & \begin{tabular}{r|}
51.9 \\
29.2 \\
8.5 \\
49.2 \\
12.2 \\
7.2 \\
7.2
\end{tabular} & $\begin{array}{c}\text { Ref. } \\
1.3(0.6-3.0) \\
2.8(1.3-6.1) \\
\quad \text { Ref. } \\
2.2(1.3-3.6) \\
2.8(1.7-4.7)\end{array}$ & $\begin{array}{r}0.5431 \\
0.0074 \\
\\
0.0040 \\
<0.0001\end{array}$ & 0.0198 \\
\hline
\end{tabular}

Table 2. Correlation between histological categorisation of the EMT status in the primary tumour (Histology ${ }^{\text {EMT }}$ ) and other prognostic factors

Cohort 1

\begin{tabular}{|l|}
\cline { 2 - 2 } \multicolumn{1}{c|}{} \\
\hline Parameters \\
\hline $\begin{array}{l}\text { Tumour } \\
\text { diameter }(\mathrm{mm})\end{array}$ \\
\hline Tumour grade \\
\hline G1 \\
G2 \\
G3
\end{tabular}

Low-grade

High-grade

Venous invasion

Low-grade

High-grade

$T$ stage

T2

T3

$\mathrm{T} 4$

$\mathrm{N}$ stage

NO

N1

N2

M substage

M1a

M1b

Histology ${ }^{\mathrm{EMT}}$

Category A 51.0

Category B

74 (35.2)

45 (18.2)

9 (20.9)

$117(55.7)$
$169(68.4)$
$28(65.1)$

$120(31.6)$

$8(6.7)$

233 (61.3)

$81(67.5)$

21 (13.8)

$211(60.6)$

66 (62.9)

$11(10.5)$

$66(62.9)$

\begin{tabular}{l|l}
$91(36.7)$ & $141(56.9)$ \\
$31(16.0)$ & $132(68.0)$
\end{tabular}

$6(10.3)$

$41(70.7)$
27 (7.1)

$31(25.8)$

$<0.0001$

$7(8.8)$
$1(0.9)$

$1(0.9)$

$<0.0001$

30 (8.6)

28 (18.4)

$4(6.5)$
$4(3.0)$

$4(3.0)$

$<0.0001$

0
$30(8.1)$

$28(26.7)$

\begin{tabular}{|l}
$16(6.5)$ \\
$31(16.0)$ \\
$11(19.0)$
\end{tabular}

$11(19.0)$

-

\begin{tabular}{l|l|l}
- & $7(5.8)$
\end{tabular}

$1(1.3)$

$1(33.3)$
$5(5.4)$
$2(2.0)$

\begin{tabular}{l|l}
$<0.0001$ & $5(11.6)$ \\
& $2(2.6)$ \\
& $1(1.3)$
\end{tabular}

$2(2.6)$

$(1.3)$

\begin{tabular}{l|l}
\hline$(9.3)$ & $27(62.8)$ \\
$(2.5)$ & $60(50.0)$ \\
$(3.0)$ & $16(48.5)$
\end{tabular}

Cohort 2

Resectability of distant metastasis

\begin{tabular}{|c|c|c|c|c|c|c|c|}
\hline $\begin{array}{l}\text { Resectable } \\
\text { Unresectable }\end{array}$ & - & - & - & $\begin{array}{l}3(4.7) \\
5(3.8)\end{array}$ & $\begin{array}{l}38(59.4) \\
65(49.2)\end{array}$ & $\begin{array}{l}23(35.9) \\
62(47.0)\end{array}$ & 0.3435 \\
\hline Serum CEA $\left(\mu \mathrm{gl}^{-1}\right)$ & - & - & - & 55.1 & 213.6 & 213.8 & $0.9825^{a}$ \\
\hline
\end{tabular}

Serum CEA $\left(\mu \mathrm{gl}^{-1}\right)$

一

-

55.1

Histology ${ }^{\text {EMT }}$

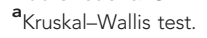

Cohort 2. According to Histology ${ }^{\mathrm{EMT}}$, the 5-year OS rates were $71.4 \%, 21.2 \%$ and $4.1 \%$ for categories A, B and C, respectively $(P<0.0001)$. As shown in Figure 4 , the significant impact of Histology ${ }^{\mathrm{EMT}}$ on OS was observed when we analysed patients with resectable and with unresectable disease individually, that is, the results of survival were favourable in the order of category A, B and $\mathrm{C}$ in both groups. In the resectable group, the 5-year OS rates were $54.1 \%$ for category B and $15.6 \%$ for category C $(P=0.0021)$. In the 

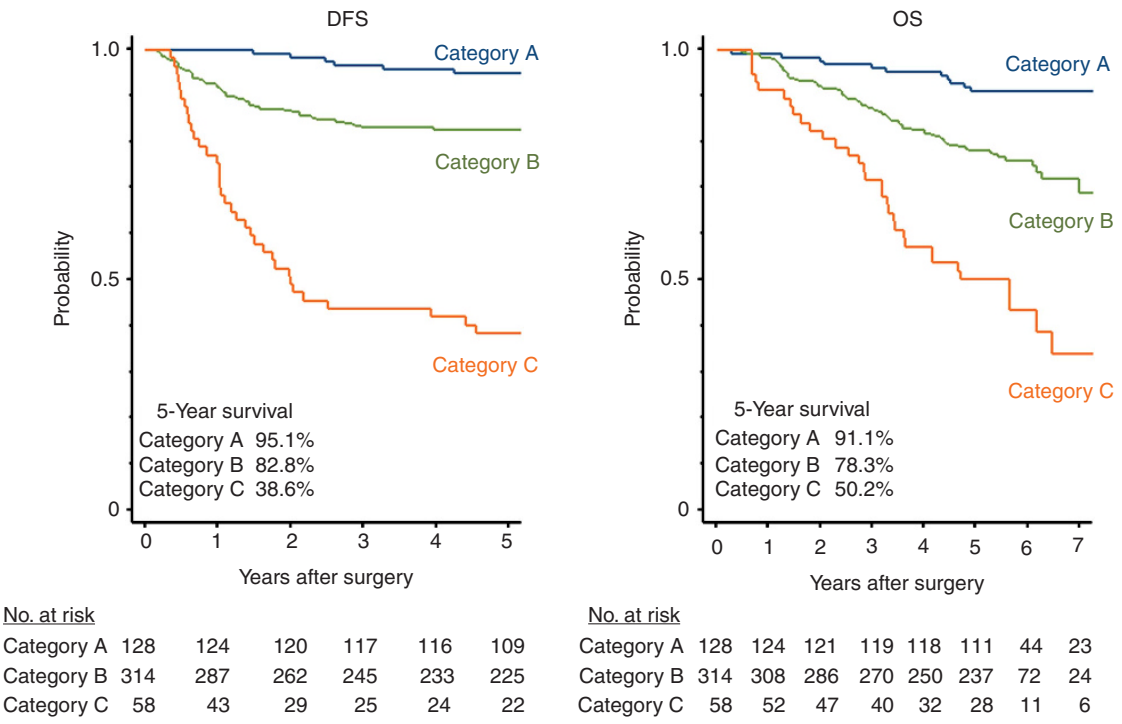

Figure 3. Survival estimates by the Kaplan-Meier method in cohort 1 according to Histology ${ }^{E M T}$. Disease-free survival: categories $A$ vs $B$, $P=0.0005$; categories $A$ vs $C, P<0.0001$; categories $B$ vs $C, P<0.0001$. OS: categories $A$ vs $B, P=0.0002$; categories $A$ vs $C, P<0.0001$; categories $B$ vs $C, P<0.0001$. Abbreviations: $D F S=$ disease-free survival; $O S=$ overall survival.
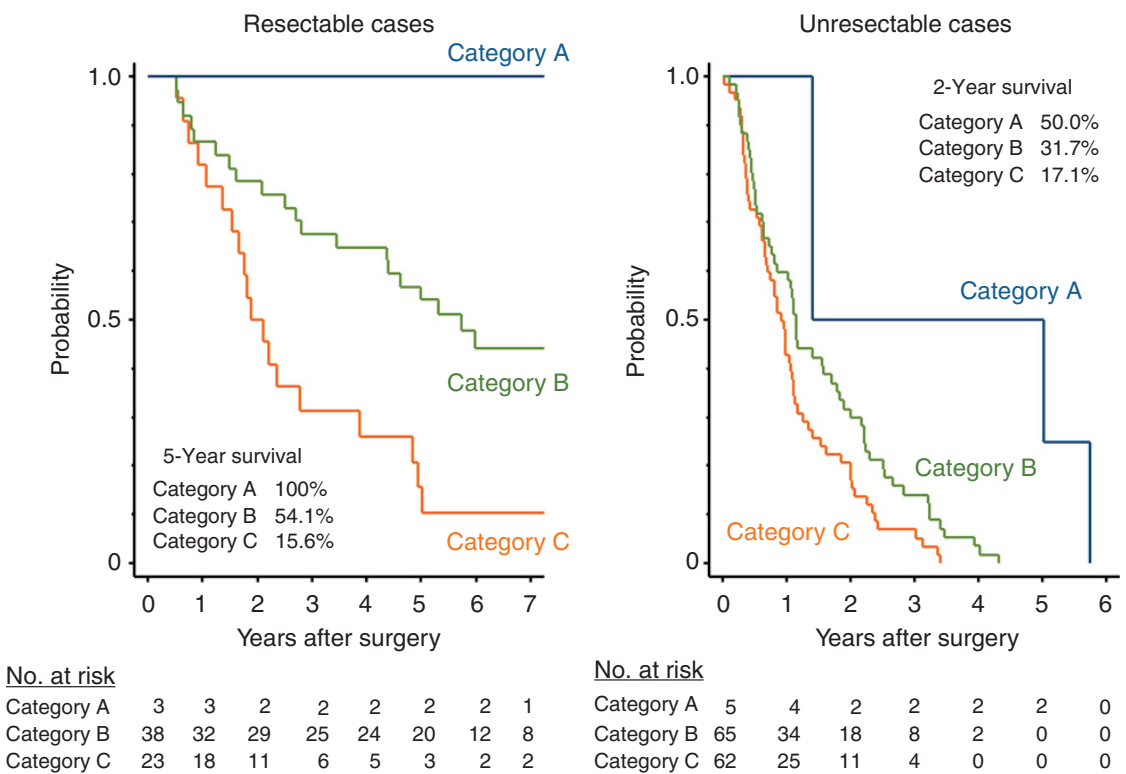

Figure 4. Survival estimates by the Kaplan-Meier method in cohort 2 according to Histology ${ }^{\mathrm{EMT}}$. Resectable group: categories $B$ vs $C, P=0.0021$ ( $P$-value for categories $A$ and $B$ or $C$ cannot be calculated because of the lack of cases with event). Unresectable group: categories $A$ vs $B$, $P=0.0168$; categories $A$ vs $C, P=0.0091$; categories $B$ vs $C, P=0.0261$.

unresectable group, a significant difference was observed in the probability of OS between each category: the 2-year OS rates were highest for category A $(50.0 \%)$, followed by categories B $(31.7 \%)$ and $\mathrm{C}(17.1 \%)$.

Comparison of prognostic stratification ability among prognostic parameters. Among the potential prognostic factors, multivariate analysis based on Cox proportional hazards model identified Histology ${ }^{\mathrm{EMT}}$, $\mathrm{N}$ stage, lymphatic invasion and tumour location as independent prognostic markers of OS in cohort 1 (Table 3). In cohort 2, independent prognostic markers selected by multivariate analysis included grade, $M$ substage and Histology ${ }^{\mathrm{EMT}}$.

A comparison of the ability to stratify patient prognostic outcomes according to conventional tumour grading and staging parameters is presented in Table 4 . In cohort 1, Histology showed the most favourable AIC among the parameters analysed. In cohort $2, \mathrm{M}$ substage showed the most favourable AIC, followed by tumour differentiation grade. Histology ${ }^{\mathrm{EMT}}$ showed a more favourable AIC than $\mathrm{T}$ or $\mathrm{N}$ stage, and the range of 5-year OS rate allocated in each category was the widest in Histology ${ }^{\mathrm{EMT}}$ among the prognostic parameters analysed.

\section{DISCUSSION}

Colorectal cancer is a clinically diverse disease in terms of oncologic outcomes. At present, basic research is focused on the cancer microenvironment of individual tumours to explore tumour heterogeneity (Hanahan and Weinberg, 2011). It is increasingly apparent that the crosstalk between cancer cells and cells of the neoplastic stroma is involved in the acquired capability for invasive 
Table 3. Univariate and multivariate analyses for overall survival by the Cox proportional hazards regression model

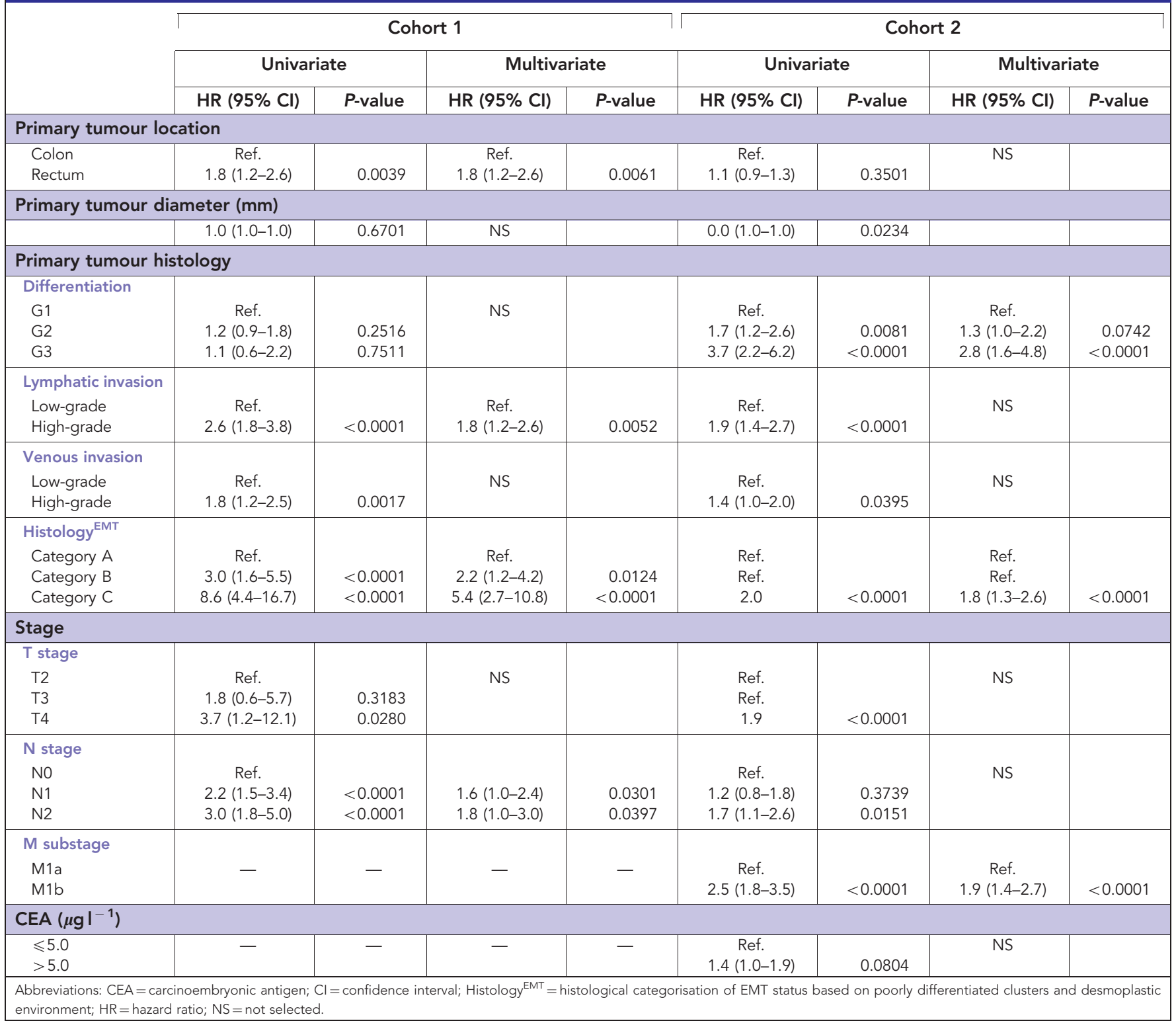

growth and metastasis through the induction of EMT (Kalluri and Zeisberg, 2006; Joyce and Pollard, 2009; Hanahan and Weinberg, 2011). The EMT concept provides a new basis for understanding the progression of carcinoma towards dedifferentiated and more malignant states.

Nuclear $\beta$-catenin accumulation, which is evidence of $\mathrm{Wnt} / \beta$ catenin activation and may facilitate colon cancer cells to lose epithelial differentiation and undergo EMT (Hlubek et al, 2007; Fodde and Brabletz, 2007), is often regarded as the histological trait of EMT in colon cancer (Thiery, 2002; Brabletz et al, 2005). In the present study, we have proposed a new histological approach for assessing the EMT potential in individual CRCs, that is, an integrated evaluation of two EMT-associated histological features, the dedifferentiation phenotype of cancer cells and the pro-EMT desmoplastic environment (Figure 1). Cancer-associated fibroblasts are key components that modulate the cancer microenvironment and facilitate the progression of carcinoma towards a dedifferentiated phenotype in a direct or indirect manner through the remodelling of the ECM (Kalluri and Zeisberg, 2006; Karagiannis et al, 2012). Further, CAFs have been reported to have a direct role in the induction of EMT by producing Wnt ligands for paracrine signalling in tumour invasion front cells and an indirect role by producing growth factors and cytokines that activate $\mathrm{Wnt} / \beta$ catenin signalling (Karagiannis et al, 2012). In addition, CAFs generate an altered ECM environment, which interacts directly with tumour cells to influence functions such as proliferation, apoptosis, migration and differentiation (Allen and Jones, 2011). Integrated assessment of morphological alteration at the tumour's leading edge focusing on PDCs and DR (Histology ${ }^{\mathrm{EMT}}$ ) may therefore become a practical methodology that enables understanding of the potential of EMT in individual CRCs at the histological level.

Poorly differentiated clusters predominantly appear at the tumour front and are closely associated with an upregulated $\mathrm{Wnt} / \beta$-catenin signalling pathway. As we reported previously, L1 cell adhesion molecule (L1CAM), one of the targets of the Wnt/ $\beta$ catenin signalling pathway that strongly induces epithelial cell migration, was upregulated in PDCs (Kajiwara et al, 2011a). In addition, the relative mRNA expressions of metalloproteinases, such as matrix metalloproteinase (MMP)-7 and MMP-9, and a disintegrin and metalloproteinases (ADAM)-12, were shown to be significantly higher in PDCs than in tumour nests with gland 
Table 4. Comparison of grading and staging systems in terms of the ability to stratify patient prognostic outcomes by the results of overall survival

\begin{tabular}{|c|c|c|c|c|c|c|c|}
\hline \multirow[b]{2}{*}{$\begin{array}{l}\text { Prognostic } \\
\text { parameter }\end{array}$} & \multirow[b]{2}{*}{ Categories } & \multicolumn{3}{|c|}{ Cohort 1} & \multicolumn{3}{|c|}{ Cohort 2} \\
\hline & & No. of cases & 5 -Year OS (\%) & AIC & No. of cases & 5 -Year OS (\%) & AIC \\
\hline Tumour differentiation & $\begin{array}{l}\text { G1 } \\
\text { G2 } \\
\text { G3 }\end{array}$ & $\begin{array}{r}210 \\
247 \\
43\end{array}$ & $\begin{array}{l}79.6 \\
77.5 \\
76.7\end{array}$ & 1432.6 & $\begin{array}{r}43 \\
120 \\
33\end{array}$ & $\begin{array}{r}29.6 \\
12.9 \\
3.8\end{array}$ & 1436.6 \\
\hline Histology ${ }^{\text {EMT }}$ & $\begin{array}{l}\text { Category A } \\
\text { Category B } \\
\text { Category C }\end{array}$ & $\begin{array}{r}128 \\
314 \\
58\end{array}$ & $\begin{array}{l}91.1 \\
78.3 \\
50.2\end{array}$ & 1386.0 & $\begin{array}{r}8 \\
103 \\
85\end{array}$ & $\begin{array}{r}71.4 \\
21.2 \\
4.1\end{array}$ & 1440.0 \\
\hline T stage & $\begin{array}{l}\mathrm{T} 2 \\
\text { T3 } \\
\text { T4 }\end{array}$ & $\begin{array}{r}26 \\
369 \\
105\end{array}$ & $\begin{array}{l}88.5 \\
80.9 \\
66.7\end{array}$ & 1418.8 & $\begin{array}{r}3 \\
92 \\
101\end{array}$ & $\begin{array}{r}50.0 \\
22.0 \\
8.4\end{array}$ & 1443.6 \\
\hline $\mathrm{N}$ stage & $\begin{array}{l}\text { N0 } \\
\text { N1 } \\
\text { N2 }\end{array}$ & $\begin{array}{r}248 \\
194 \\
58\end{array}$ & $\begin{array}{l}87.2 \\
71.1 \\
65.0\end{array}$ & 1410.5 & $\begin{array}{l}43 \\
78 \\
75\end{array}$ & $\begin{array}{r}26.4 \\
16.5 \\
7.6\end{array}$ & 1453.9 \\
\hline M substage & $\begin{array}{l}\text { M1a } \\
\text { M1b }\end{array}$ & - & - & - & $\begin{array}{r}120 \\
76\end{array}$ & $\begin{array}{r}24.3 \\
1.4\end{array}$ & 1428.9 \\
\hline
\end{tabular}

formation located at the invasive front (Kajiwara et al, 2011b). These results were consistent with the observation that the expression of nuclear $\beta$-catenin predominantly appears not only in single cells but also in dedifferentiated cell clusters at the tumour-host interface (Jung et al, 2001), which are believed to have undergone or are in the process of undergoing EMT (Brabletz et al, 2005; Hlubek et al, 2007; Karagiannis et al, 2012).

To histologically categorise DR, we have shed light on two distinctive ECM types produced by CAFs, that is, keloid-like collagen and myxoid stroma, as benchmarks. These two stromal components are transitory phenotypes that appear only at a desmoplastic front. It can be safely said that our proposed method is to characterise DR in individual CRC 'qualitatively' and is different from previous attempts to characterise DR 'quantitatively' with the yardstick of the tumour-stroma ratio (Mesker et al, 2007; West et al, 2010). The existence of keloid-like collagen, immunohistochemically characterised by an excessive deposition of type 1 collagen (Ueno et al, 2002), indicates that CAFs adjacent to keloid-like collagen were aberrantly activated to function as metabolic modulators, possibly as fibroblasts in keloids. Myxoid stroma, histologically characterised by excessive synthesis of a nonfibrous ECM component, dense distribution of myofibroblasts and sparse distribution of immune cells (Ueno et al, 2004), can be regarded as an ultimate form of ECM remodelling induced by tumours. Tumour cells located next to or within myofibroblastrich regions were shown to have a much higher incidence of containing nuclear-localized $\beta$-catenin, directly arguing for microenvironment-modulated WNT signalling (Medema and Vermeulen, 2011). Thus, keloid-like collagen and myxoid stroma can be regarded as histological features closely associated with EMT induction of tumour cells.

Our study demonstrated that PDC grade and DR categorisation were independently related to prognostic outcomes, and integrated assessment of these parameters may distinguish the EMT status more distinctly than assessment of individual parameters. In tumours classified in Histology ${ }^{\text {EMT }}$ category C, CAFs supposedly form the pro-EMT microenvironment and result in aggressive tumour histology with dedifferentiation and a migratory phenotype at the invasion front. Conversely, CAFs are not functioned towards facilitating EMT of carcinoma cells and the dedifferentiation programme is likely to be inactive in tumours classified in category A. In both cohorts examined in the present study, Histology ${ }^{\mathrm{EMT}}$ allowed the identification of a patient group with extremely favourable prognostic estimates as well as a patient group with extremely unfavourable prognostic estimates.

In cohort 1, Histology ${ }^{\mathrm{EMT}}$ had a better prognostic stratification power than conventional indicators including staging factors and conventional histological parameters adopted as treatment decision-making factors in current international guidelines (National Comprehensive Cancer Network, 2014). Histology ${ }^{\text {EMT }}$ enabled identification of a patient group with very favourable prognostic estimates, such as the 95\% 5-year DFS for category A. In contrast, the prognostic outcome of CRC patients with tumours classified as category $\mathrm{C}$ was very poor; the estimated figures of 5-year DFS after surgery (39\%) in this group may be comparable to those of CRC patients with resectable single metastasis in the liver (Beppu et al, 2012). Thus, by stratifying patients into groups with considerably different degrees of recurrence risk, Histology ${ }^{\text {EMT }}$ could be expected to have a potential role in a personalised approach to clinical decision making in CRC treatment, such as in determining chemotherapy regimens and surveillance schedule.

Histology ${ }^{\mathrm{MT}}$ demonstrated an ability to distinguish prognostic outcomes in cohort 2 . With respect to prognostic determinants in stage IV CRC patients, radical resection of distant metastasis is currently regarded as most important (Chen et al, 2013; Kobayashi et al, 2013), followed by parameters associated with anatomical extent of disease and performance status (Kobayashi et al, 2013; Stillwell et al, 2011). In general, primary tumour histology has not been regarded as a key prognostic indicator in the metastatic CRC setting, although a few pathological features, such as tumour grade (Kobayashi et al, 2013) and tumour-infiltrating lymphocytes (Lee et al, 2013), have been reported as independent prognostic factors. In the present study, Histology ${ }^{\mathrm{EMT}}$ was shown to have a prognostic value not only in resectable cases but also in unresectable cases. Notably, prognostic impact of Histology ${ }^{\mathrm{EMT}}$ was independent of TNM's M substage (M1a/M1b), a representative index of anatomical extent of disease in stage IV CRCs. Primary tumour histology may have to be evaluated in greater detail in clinical studies in the stage IV setting because it may potentially bias survival results much more than the contents of a chemotherapy regimen.

Neoadjuvant systemic chemotherapy is highly expected to improve the prognostic results of stage IV CRC patients with 
potentially resectable distant metastasis (Nordlinger et al, 2008), by eradicating systemic occult disease to decrease recurrence after metasectomy and by avoiding surgery in patients with rapidly progressive disease (Chua et al, 2010). On the other hand, this practice could have the potential risk of tumour progression while on chemotherapy and chemotherapy-associated toxic events, which may delay surgical resection or make it impossible in some cases (Fernandez et al, 2005). At present, the optimal indication of neoadjuvant chemotherapy for stage IV patients remains unclear (Chua et al, 2010), although tumour biology could be closely related to the appropriateness of administrating neoadjuvant chemotherapy (Adam et al, 2010). In this respect, Histology ${ }^{\mathrm{EMT}}$ could become an important indicator, contributing to the effective selection of patients who benefit from neoadjuvant chemotherapy.

The CAF-associated local microenvironment is currently believed to have key roles in modulating cancer stem cell phenotypes in vivo (Allen and Jones, 2011; Ashley, 2013). According to the 'migrating cancer stem (MCS) cells' concept (Brabletz et al, 2005), MCS cells, which are derived from stationary cancer stem cells through the acquisition of transient EMT in addition to stemness, appear at the tumour-host interface in a tumour. Potential MCS cells in CRCs are reportedly characterised by high levels of nuclear $\beta$-catenin expression and can disseminate and form metastatic colonies if they retain stem cell functionality (Brabletz et al, 2005). Poorly differentiated clusters, which are predominantly located at the invasive front in tumours with a proEMT desmoplastic environment and exert a potent impact on oncological outcomes (Barresi et al, 2012; Ueno et al, 2012, 2014), may comprise a tumour cell population possessing two decisive traits of MCS cells, that is, stemness and mobility. It should be emphasised that Histology ${ }^{\text {EMT }}$ assessment does not require any special molecular biology technique or immunohistochemical staining; it enables grading of the EMT potential of cancer cells and possibly the incidence of MCS cells only on the basis of HEstained pathological specimens. Histology ${ }^{\mathrm{EMT}}$ assessment could form a bridge between the results of bench work and pathological practice for cancer treatment.

.In conclusion, a tumour grading system based on integrated assessment of the dedifferentiation phenotype and unfavourable desmoplastic environment provides more individualised outcome prediction than conventional grading and staging systems. We believe that Histology ${ }^{\mathrm{EMT}}$ has the potential to be developed into a useful tool for understanding the essential role of EMT in determining the biological characteristics of CRCs and the underlying causes of prognostic heterogeneity in CRCs. Further attempts including multicentrer studies to validate our results and occasions of educational and training programs to establish a satisfactory reproducibility of diagnosis are needed for this system to enter routine pathology practice.

\section{REFERENCES}

Adam R, Bhangui P, Poston G, Mirza D, Nuzzo G, Barroso E, Ijzermans J, Hubert C, Ruers T, Capussotti L, Ouellet J-F, Laurent C, Cugat E, Colombo PE, Milicevic M (2010) Is perioperative chemotherapy useful for soloitary, metachronous, colorectal liver metastases? Ann Surg 252: $774-787$.

Akaike H (1973) Information theory and an extension of the maximum likelihood principle. 2nd International Symposium on Information Theory. Akademia Kiado: Budapest.

Allen M, Jones L (2011) Jekyll and Hyde: the role of the microenvironment on the progression of cancer. J Pathol 223: 162-176.

Ashley N (2013) Regulation of intestinal cancer stem cells. Cancer Lett 38: 120-126.

Barresi V, Bonetti LR, Branca G, Gregorio CD, de Leon MP, Tuccari G (2012) Colorectal carcinoma grading by quantifying poorly differentiated cell clusters is more reproducible and provides more robust prognostic information than conventional grading. Virchows Arch 461: 621-628.
Beppu T, Sakamoto Y, Hasegawa K, Honda G, Tanaka K, Kotera Y, Nitta H, Yoshidome H, Hatano E, Ueno M, Takamura H, Baba H, Kosuge T, Kokudo N, Takahashi K, Endo I, Wakabayashi G, Miyazaki M, Uemoto S, Ohta T, Kikuchi K, Yamaue H, Yamamoto M, Takada T (2012) A nomogram predicting disease-free survival in patients with colorectal liver metastases treated with hepatic resection: multicenter data collection as a Project Study for Hepatic Surgery of the Japanese Society of HepatoBiliary-Pancreatic Surgery. J Hepatobiliary Pancreat Sci 19: 72-84.

Brabletz T, Jung A, Spaderna S, Hlubek F, Kirchner T (2005) Migrating cancer stem cells-an integrated concept of malignant tumour progression. Nat Rev Cancer 5: 744-749.

Chen Y-G, Liu X, Wang X-S (2013) Classifying the stage IV colorectal cancer: prognostic impact of radical resection for colorectal liver metastases and proposal for a new staging system. Cell Biochem Biophys 67: 1445-1449.

Chua TC, Saxena A, Liauw W, Kokandi A, Morris DL (2010) Systematic review of randomized and nonrandomized trials of the clinical response and outcomes of neoadjuvant systematic chemotherapy for resectable colorectal liver metastases. Ann Surg Oncol 17: 492-501.

Edge SB, Compton CC (2010) The American Joint Committee on Cancer: the 7th Edition of the AJCC Cancer Staging Manual and the Futher of TNM. Ann Surg Oncol 17: 1471-1474.

Fernandez FG, Ritter J, Goodwin JW, Linehan DC, Hawkins WG, Sttasberg SM (2005) Effect of steathepatitis associated with irinotecan or oxaliplatin pretreatment on resectability of hepatic colorectal metastases. J Am Coll Surg 200: 845-853.

Fodde R, Brabletz T (2007) Wnt/b-catenin signaling in cancer stemness and malignant behavior. Curr Opin Cell Biol 19: 150-158.

Hanahan D, Weinberg RA (2011) Hallmarks of cancer: the next generation. Cell 144: 646-674.

Hlubek F, Brabletz T, Budczies J, Pfeiffer S, Jung A, Kirchner T (2007) Heterogeneous expression of $\mathrm{Wnt} / \mathrm{b}$-catenin target genes within colorectal cancer. Int J Cancer 121: 1941-1948.

Japanese Society for Cancer of the Colon and Rectum (2009) Japanese Classification of Colorectal Carcinoma (2nd English edn). Kanehara \& Co., Ltd.: Tokyo, Japan.

Joyce JA, Pollard JW (2009) Microenvironmental regulation of metastasis. Nat Rev Cancer 9: 239-252.

Jung A, Schrauder M, Oswald U, Knoll C, Sellberg P, Palmqvist R, Niedobitek C, Brabletz T, Kirchner T (2001) The invasion front of human colorectal adenocarcinomas shows co-localization of nuclear b-catenin, cyclin D1, and $16^{\mathrm{INK} 4 \mathrm{~A}}$ and is a region of low proliferation. Am J Pathol 159: 1613-1617.

Kajiwara Y, Ueno H, Hashiguchi Y, Shinto E, Shimazaki H, Mochizuki H, Hase K (2011a) Expression of L1 cell adhesion molecule and morphologic features as the invasive front of colorectal cancer. Am J Clin Pathol 136: 138-144.

Kajiwara Y, Ueno H, Hashiguchi Y, Shinto E, Shimazaki H, Mochizuki H, Hase K (2011b) Heterogeneity of metalloproteinase expression in colorectal cancer - relation of molecular findings to basic morphology. Anticancer Res 31: 1567-1576.

Kalluri R, Zeisberg M (2006) Fibroblasts in cancer. Nat Rev Cancer 6: 392-401.

Karagiannis GS, Poutahidis T, Erdman SE, Kirsch R, Riddell RH, Diamandis EP (2012) Cancer-associated fibroblasts drive the progression of metastasis through both paracrine and mechanical pressure on cancer tissue. Mol Cancer Res 10: 1403-1418.

Kobayashi H, Kotake K, Sugihara K (2013) Prognostic scoring system for stage IV colorectal cancer: is the AJCC sub-classification of stage IV colorectal cancer appropriate? Int J Clin Oncol 18: 696-703.

Lee W-S, Kang M, Bae J-H, Lee J-I, Ha SY (2013) Clinical impact of tumorinfiltrating lymphocytes for survival in curatively resected stage IV colon cancer with isolated liver or lung metastasis. Ann Surg Oncol 20: 697-702.

McAllister SS, Weinberg RA (2010) Tumor-host interactions: a far-reaching relationship. J Clin Oncol 28: 4022-4028.

Medema JP, Vermeulen L (2011) Microenvironmental regulation of stem cells in intestinal homeostasis and cancer. Nature 474: 318-326.

Mesker WE, Junggeburt JMC, Szuhai K, de Heer P, Morreau H, Tanke HJ, Tollenaar AEM (2007) The carcionma-stromal ratio of colon carcinoma is an independent factor for survival compared to lymph node status and tumor stage. Cell Oncol 29: 387-398.

National Comprehensive Cancer Network (2014) NCCN clinical practice guidelines in oncology-colon cancer (version 3. 2014) http:// www.nccn.org/professionals/physician_gls/pdf/colon.pdf, accessed 20 March 2014. 
Nordlinger B, Sorbye H, Glimelius B, Poston GJ, Schlag PM, Rougier P, Bechstein WO, Primrose JN, Walpole ET, Finch-Jones M, Jaeck D, Mirza D, Parks RW, Collette L, Praet M, Bethe U, Cutsem EV, Scheithauer W, Gruenberger T (2008) Perioperative chemotherapy with FOLFOX4 and surgery versus surgery alone for resectable liver metastases from colorectal cancer (EORTC Intergroup trial 40983): a randomised controlled trial. Lancet 371: 1007-1016.

Sobin L, Gospodarowicz M, Wittekind C (eds) (2009) TNM Classification of Malignant Tumours (7th edn). Wiley-Blackwell: West Sussex, UK.

Stillwell AP, Ho Y-H, Veitch C (2011) Systematic review of prognostic factors related to overall survival in patients with stage IV colorectal cancer and unresectable metastases. World J Surg 35: 684-692.

Thiery JP (2002) Epithelial-mesenchymal transitions in tumour progression. Nat Rev Cancer 2: 442-454.

Ueno H, Hase K, Hashiguchi Y, Shimazaki H, Tanaka M, Miyake O, Masaki T, Shimada Y, Kinugasa Y, Mori Y, Kishimoto M, Kameoka S, Sato Y, Matsuda K, Nakadoi K, Shinto E, Nakamura T, Sugihara K (2014) Site-specific tumor grading system in colorectal cancer: multicenter pathological review of the value of quantifying poorly differentiated clusters. Am J Surg Pathol 38: 197-204.
Ueno H, Jones A, Jass JR, Talbot IC (2002) Clinicopathological significance of the 'keloid-like' collagen and myxoid stroma in adnvaced rectal cancer. Histopathology 40: 327-334.

Ueno H, Jones AM, Wilkinson KH, Jass JR, Talbot IC (2004) Histological categorisation of fibrotic cancer stroma in advanced rectal cancer. Gut 53 : 581-586.

Ueno H, Shimazaki H, Shinto E, Hashiguchi Y, Nakanishi K, Maekawa K, Katsurada Y, Nakamura T, Mochizuki H, Yamamoto J, Hase K (2012) New criteria for histologic grading of colorectal cancer. Am J Surg Pathol 36: 193-201.

West NP, Dattani M, McShane P, Hutchins G, Grabsch J, Mueller W, Treanor D, Quirke P, Grabsch H (2010) The proportion of tumour cells is an independent predictor for survival in colorectal cancer patients. Br J Cancer 102: 1519-1523.

Wolpin BM, Mayer RJ (2008) Reviews in basic and clinical gastroenterology. Gastroenterology 134: 1296-1310.

This work is published under the standard license to publish agreement. After 12 months the work will become freely available and the license terms will switch to a Creative Commons AttributionNonCommercial-Share Alike 3.0 Unported License. 